ARTICLE

https://doi.org/10.1038/s41467-019-13183-5

\title{
Enantiodivergence by minimal modification of an acyclic chiral secondary aminocatalyst
}

\author{
Jun Dai ${ }^{1}$, Zhuang Wang ${ }^{1}$, Yuhua Deng ${ }^{1}$, Lei Zhu², Fangzhi Peng ${ }^{1}$, Yu Lan ${ }^{2 \star} \&$ Zhihui Shao ${ }^{1 \star}$
}

The development of enantiodivergent catalysis for the preparation of both enantiomers of a chiral compound is of importance in pharmaceutical and bioorganic chemistry. With the design of a class of reactive and stereoselective organocatalysts, acyclic chiral secondary amines, a method for achieving the enantiodivergence is developed simply by changing the secondary $\mathrm{N}$-i-Bu- to $\mathrm{N}$-Me-group within the catalyst architecture while maintaining the same absolute configuration of the catalysts, which modulates the catalyst conformation. This catalyst-controlled enantiodivergent method not only enables challenging asymmetric transformations to occur in an enantiodivergent manner but also features a high level of stereocontrol and broad scope that is demonstrated in eight different reactions (90 examples), all delivering both enantiomers of a range of structurally diverse products including hitherto less accessible, yet important, compounds in good yields with high stereoselectivities.

\footnotetext{
${ }^{1}$ Key Laboratory of Medicinal Chemistry for Natural Resource, School of Chemical Science and Technology, and State Key Laboratory for Conservation and Utilization of Bio-Resources in Yunnan, Yunnan University, 650091 Kunming, China. ${ }^{2}$ School of Chemistry and Chemical Engineering, Chongqing Key Laboratory of Theoretical and Computational Chemistry, Chongqing University, 400030 Chongqing, China. *email: lanyu@cqu.edu.cn; zhihui_shao@hotmail.com
} 
D ifferent enantiomers of a biologically active molecule generally have different or even opposite biological activities ${ }^{1}$. For example, $(2 S, 3 S)$-paclobutrazol is a plant growth regulator while $(2 R, 3 R)$-paclobutrazol is a fungicide ${ }^{2}$. Enantiodivergent syntheses through catalytic asymmetric transformations are one of the most powerful and economical approaches for the stereoselective synthesis of both enantiomeric products ${ }^{3-24}$. Although impressive advances have been made, existing catalytic enantiodivergent methods are still limited in scope and may not be suitable for all desired transformations. Meanwhile, there appears a growing number of challenging transformations that cannot be catalyzed effectively by existing chiral catalysts. Thus the development of chiral catalysts and methods enabling challenging asymmetric transformations to occur in an enantiodivergent manner remains significant challenges.

In asymmetric aminocatalysis, chiral secondary amines employed are usually cyclic ${ }^{25-34}$. The rationale is that the cyclic strain increases the nucleophilicity of the amine and the cyclic structure limits bond rotation, providing a well-organized chiral environment. In contrast, acyclic chiral secondary aminocatalysts with both reactivity and stereochemical control comparable to cyclic chiral secondary aminocatalysts remain elusive ${ }^{35}$. Meanwhile, the application of acyclic chiral secondary aminocatalysts in enantiodivergent transformations is not reported.

Herein we describe our studies on designing and engineering acyclic chiral secondary aminocatalysts for enantiodivergent, asymmetric reactions. By strategically changing the (achiral) secondary $\mathrm{N}-\mathrm{i}$ - $\mathrm{Bu}$ - to $\mathrm{N}$-Me-group (within the catalyst architecture) for modification of secondary amine while maintaining the same absolute configuration of the catalysts, a reversal of the enantioselectivity is achieved. This enantiodivergent strategy not only enables asymmetric transformations to occur in an enantiodivergent manner but also features broad scope and high levels of stereocontrol, as demonstrated by its application to 8 different reactions (90 examples), including 7 reactions generating 2 stereocenters, all delivering both enantiomers of structurally diverse products in good yields with good enantioselectivity and diastereoselectivity.

\section{Results}

Mannich reaction of $\beta, \gamma$-alkynyl- $\alpha$-imino esters. Acyclic chiral secondary amines I, which we designed, were easily prepared from acyclic $\alpha$-amino acids (for details, see Supplementary Note 2). First, they were tested to catalyze enantiodivergent Mannich reactions between aldehydes and C-alkynyl ketimines. The resulting products, chiral propargylamines ${ }^{36}$ bearing quaternary stereocenter ${ }^{37-39}$, are of synthetic and biological importance ${ }^{40-46}$. Although the catalytic asymmetric direct Mannich reactions of aldehydes with C-alkynyl aldimines have recently emerged ${ }^{47-50}$, the corresponding catalytic asymmetric direct Mannich reactions of aldehydes with C-alkynyl ketimines providing quaternary propargylamines have not yet been realized.

Treatment of 1a and 2a with the acyclic chiral secondary amine catalyst $\mathrm{Ia} / 0.5 \mathrm{TfOH}$ in $\mathrm{MeCN}$ at $-40^{\circ} \mathrm{C}$ afforded the corresponding Mannich product 3a in good yield; the major isomer, anti-3a with the $(3 S, 4 R)$ configuration, was obtained with $>20: 1 \mathrm{dr}($ anti/syn) and 98:2 er (Table 1, entry 1). The potential

Table 1 Optimization of the enantiodivergent Mannich reaction ${ }^{a}$
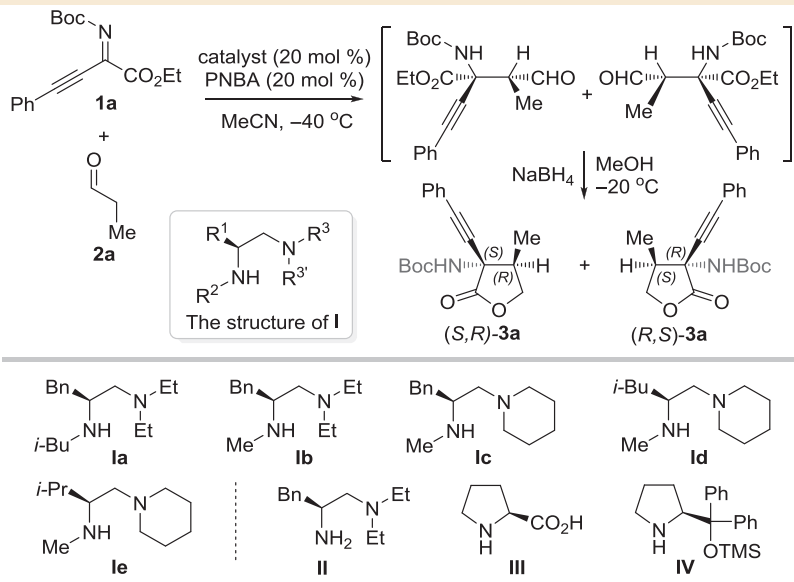

\begin{tabular}{|c|c|c|c|c|c|}
\hline Entry & Catalyst & $t[h]$ & Yield [\%] ${ }^{\mathbf{b}}$ & dr [anti/syn]c & erd \\
\hline 1 & $\mathbf{l a} / 0.5 \mathrm{TfOH}$ & 10 & 82 & $>20: 1$ & $98: 2$ \\
\hline 2 & $\mathbf{l b} / 0.5 \mathrm{TfOH}$ & 10 & 65 & $7: 1$ & $39.5: 60.5$ \\
\hline 3 & Ic/0.5 TfOH & 14 & 83 & $14: 1$ & $17: 83$ \\
\hline 4 & Id/0.5 TfOH & 14 & 87 & $8: 1$ & $8: 92$ \\
\hline 5 & $\mathrm{le} / 0.5 \mathrm{TfOH}$ & 14 & 67 & $5: 1$ & $14: 86$ \\
\hline $6^{e}$ & Id/0.5 TfOH & 10 & 78 & $>20: 1$ & $3.5: 96.5$ \\
\hline 7 & Id & 72 & Trace & - & - \\
\hline 8 & II/0.5 TfOH & 48 & Trace & - & - \\
\hline 9 & III & 48 & Trace & - & - \\
\hline 10 & IV & 48 & Trace & - & - \\
\hline
\end{tabular}

If trifluoromethanesulfony

aUnless otherwise specified, the asymmetric direct Mannich reaction of $\beta, \gamma$-alkynyl- $\alpha$-imino ester $\mathbf{1 a}(0.1 \mathrm{mmol})$ and propylaldehyde $\mathbf{2 a}$ ( $0.3 \mathrm{mmol})$ was conducted in the presence of catalyst ( $20 \mathrm{~mol} \%)$ and $\mathrm{p}-\mathrm{NO}_{2}-\mathrm{C}_{6} \mathrm{H}_{4} \mathrm{CO}_{2} \mathrm{H}(2 \mathrm{Omol} \%)$ in $\mathrm{MeCN}(0.8 \mathrm{~mL})$ at $-40^{\circ} \mathrm{C}$

bYield of isolated product

'Determined by ${ }^{1} \mathrm{H}-\mathrm{NMR}$ or HPLC

dDetermined by chiral HPLC

Dichloroethane was used as the solvent 


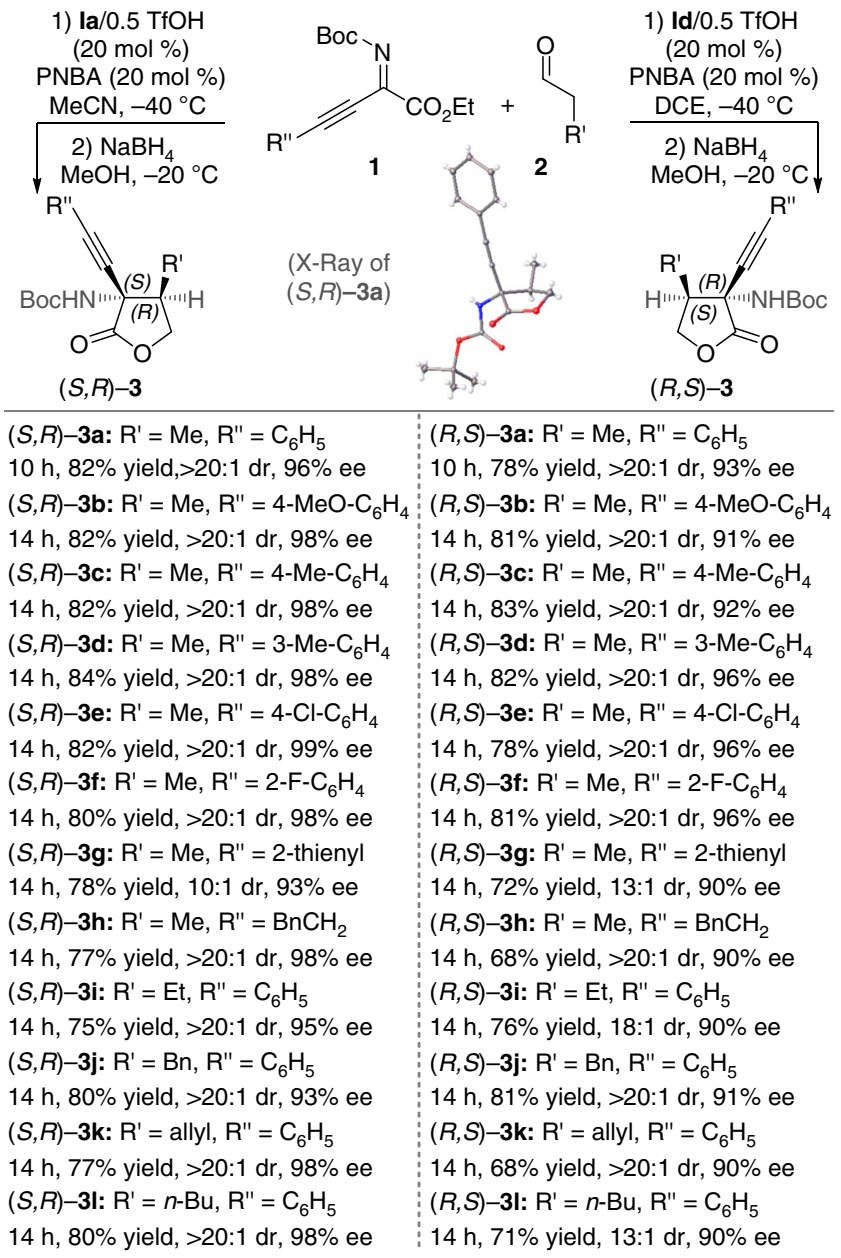

Fig. 1 Enantiodivergent Mannich reaction of $\beta, \gamma$-alkynyl- $\alpha$-imino esters. Reaction conditions for the formation of $(S, R)-\mathbf{3}: 1(0.1 \mathrm{mmol})$, PNBA $(0.02$ $\mathrm{mmol}, 20 \mathrm{~mol} \%)$, la/0.5TfOH $(0.02 \mathrm{mmol}, 20 \mathrm{~mol} \%), 2(0.3 \mathrm{mmol})$, $\mathrm{MeCN}(0.8 \mathrm{~mL}),-40^{\circ} \mathrm{C}$. Reaction conditions for the formation of $(R, S)-\mathbf{3}: \mathbf{1}$ $(0.1 \mathrm{mmol}), \mathrm{PNBA}(0.02 \mathrm{mmol}, 20 \mathrm{~mol} \%)$, Id $/ 0.5 \mathrm{TfOH}(0.02 \mathrm{mmol}, 20$ $\mathrm{mol} \%), 2(0.3 \mathrm{mmol}), \mathrm{DCE}(0.8 \mathrm{~mL}),-40^{\circ} \mathrm{C}$

1,4-addition onto the alkynyl ketimines was not observed. When secondary $N-i$-Bu was changed to $N$-Me within the catalyst architecture, a reversal of enantioselectivity was observed, and the enantiomeric Mannich product $(R, S)$-3a was obtained with $7: 1 \mathrm{dr}$ and 39.5:60.5 er (entry 2). Optimization of $\mathrm{R}^{1}$ and $\mathrm{R}^{3} / \mathrm{R}^{3}$, substituents of $\mathbf{I}$ (keeping $\mathrm{R}^{2}=\mathrm{Me}$ ) led us to identify $\mathbf{I d} / 0.5 \mathrm{TfOH}$ as the optimal catalyst for obtaining the enantiomeric Mannich product $(R, S)$-3a with good enantioselectivity and diastereoselectivity (entry 4). When dichloroethane (DCE) was used as the solvent, the diastereoselectivity and enantioselectivity of $(R, S)$-3a was further improved to $>20: 1 \mathrm{dr}$ and 3.5:96.5 er, respectively (entry 6). In order to further evaluate the efficiency of our acyclic chiral secondary amine organocatalysts, we compared the performance of Ia with the commercially available cyclic chiral secondary amine catalysts III and IV as well as the chiral primary amine catalyst II. We found that II, III, and IV could not promote the asymmetric Mannich reaction of 1a and 2a under the same conditions (Table 1, entries 8-10. For details, see Supplementary Table 1).

We then investigated the Mannich reactions between various $\beta$, $\gamma$-alkynyl-a-imino esters and aldehydes in the presence of enantiodivergent catalysts, $\mathrm{Ia} / 0.5 \mathrm{TfOH}$ and $\mathbf{I d} / 0.5 \mathrm{TfOH}$, respectively (Fig. 1). Here the use of catalyst $\mathbf{I a} / 0.5 \mathrm{TfOH}$ afforded functionalized quaternary propargylamines $(S, R)-\mathbf{3 a}-\mathbf{l}$ in good yields with both high diastereoselectivity and enantioselectivity, while the use of catalyst $\mathbf{I d} / 0.5 \mathrm{TfOH}$ gave anti-Mannich adducts $(R, S)$-3a-l with the opposite absolute configuration in good yields with both high diastereoselectivity and enantioselectivity. It is mentioned that catalytic asymmetric direct Mannich reactions of aldehydes with acyclic ketimines have not previously been realized.

Origin of the reversal of enantioselectivity. Based on the above observations and combined with density functional theory (DFT) calculations (for the details, see Supplementary Note 12), we propose the following possible transition state models (Fig. 2) to account for the observed absolute configuration of both Mannich products. In the case of $\mathbf{I a}(N-i-B u)$, the enamine Ia-int-I with ssyn $\mathrm{C}-\mathrm{N}$ skeleton is energetically favored over the enamine Ia-intII with s-anti C-N skeleton. The dominant s-syn enamine Ia-int-I is used for the $\mathrm{C}-\mathrm{C}$ bond forming step via transition state TS-I (with the tertiary ammonium $\mathrm{H}$-bonded to the imine $\mathrm{N}$ ) ${ }^{51}$; the $S i$ face of the enamine reacts with the $R e$ face of the imine. TS-II involving s-anti-enamine Ia-int-II is disfavored compared to TSI due to unfavorable steric repulsion. In contrast, in the case of Id $(\mathrm{N}-i-\mathrm{Me})$, the enamine Id-int-II with s-anti $\mathrm{C}-\mathrm{N}$ skeleton is energetically favored over the enamine Id-int-I with s-syn C-N skeleton. The $R e$ face of the s-anti enamine reacts with the $S i$ face of the imine via the favorable TS-IV, which gives the $R, S$ isomer predominantly.

Mannich reaction of trifluoromethyl alkynyl ketimines. Our developed enantiodivergent catalysts, Ia/0.5TfOH and Id/ $0.5 \mathrm{TfOH}$, could also efficiently catalyze the asymmetric direct Mannich reactions between aldehydes and trifluoromethylated alkynyl ketimines (Fig. 3). These reactions provide an enantiodivergent catalytic asymmetric synthesis of quaternary propargylamines bearing trifluoromethyl group. Installing the trifluoromethyl $\left(\mathrm{CF}_{3}\right)$ functionality into molecular architectures is an important objective in the pharmaceutical industry ${ }^{52}$. In order to further evaluate the efficiency of our acyclic chiral secondary amine organocatalysts, we compared the performance of Ia and Id with cyclic chiral secondary amine catalysts III and IV as well as chiral primary amine catalyst II. We found that II could not promote this reaction, while III and IV afforded poor enantioselectivity and diastereoselectivity with complementary relative configuration (for details, see Supplementary Table 2).

Mannich reactions of cyclic ketimines. Next, designed enantiodivergent catalysis was explored in the asymmetric direct Mannich reactions of aldehydes with cyclic ketimines. When the reactions of isatin-derived ketimines 6 with aldehydes 2 were carried out in the presence of $\mathbf{I a} / 0.5 \mathrm{TfOH}$ and $\mathrm{Id} / 0.5 \mathrm{TfOH}$, respectively, both enantiomers of the desired Mannich products, anti-7, were obtained in good yields with both high diastereoselectivity and enantioselectivity (Fig. 4). Thus these reactions provide a highly stereoselective method for the catalytic asymmetric enantiodivergent synthesis of 3-substituted 3-amino-2oxindoles ${ }^{53}$.

Designed enantiodivergent catalysis was also applicable to the unknown Mannich reaction between a monocyclic ketimine, 8, and 2a (Fig. 5). Both enantiomers of the functionalized chiral pyrazolone 9 were obtained in good yields with both high diastereoselectivity and enantioselectivity, in the presence of catalyst $\mathbf{I a} / 0.5 \mathrm{TfOH} \quad(N-i-\mathrm{Bu})$ and $\mathbf{I e} / 0.5 \mathrm{TfOH} \quad(N-\mathrm{Me})$, respectively ${ }^{54}$. 
a

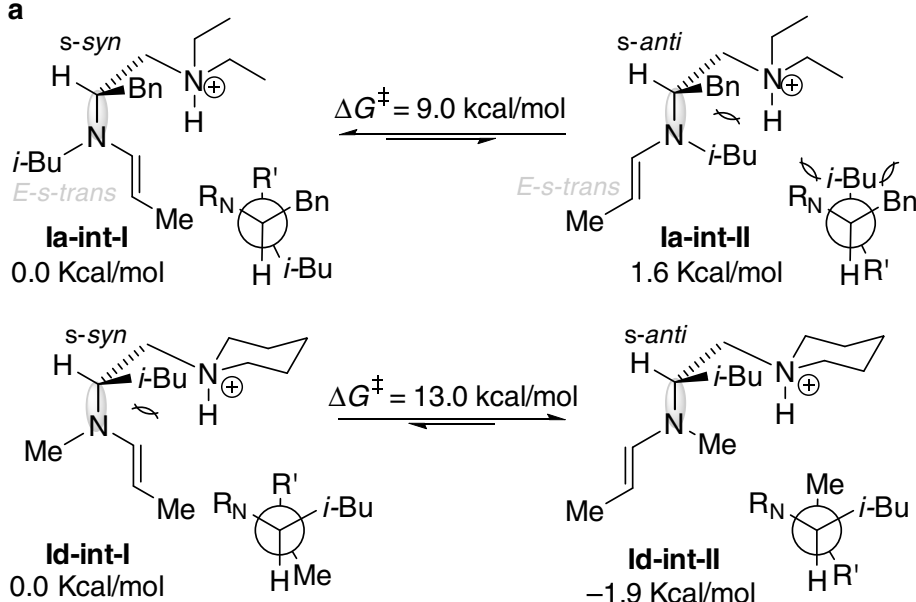

b

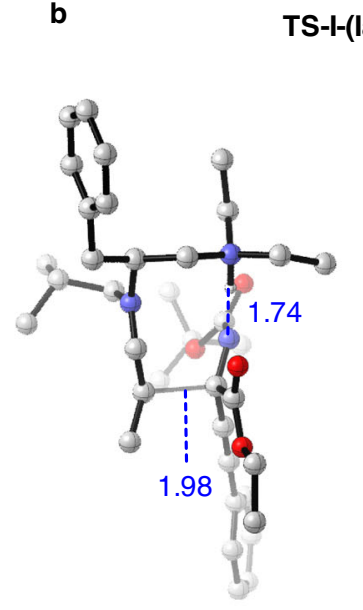

TS-I-(la-S,R)

$$
\Delta \Delta G_{298.15}^{\ddagger}=0.0 \mathrm{Kcal} / \mathrm{mol}
$$

$\Delta \Delta G_{233.15}^{\ddagger}=0.0 \mathrm{Kcal} / \mathrm{mol}$

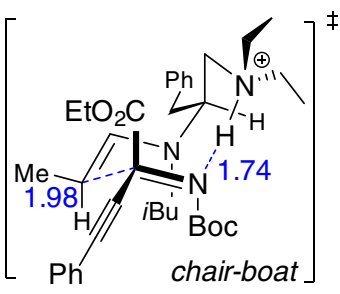

[ Ph chair-boat

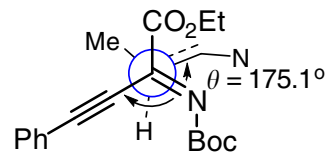

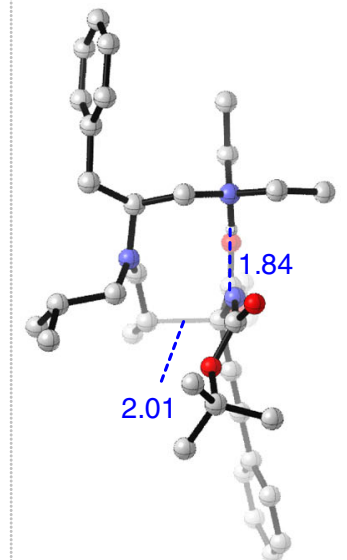

TS-II-(la- $R, S)$

$\Delta \Delta G_{298.15}^{\ddagger}=2.2 \mathrm{Kcal} / \mathrm{mol}$

$\Delta \Delta G_{233.15}^{\ddagger}=2.1 \mathrm{Kcal} / \mathrm{mol}$

chair-chair

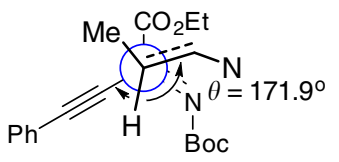

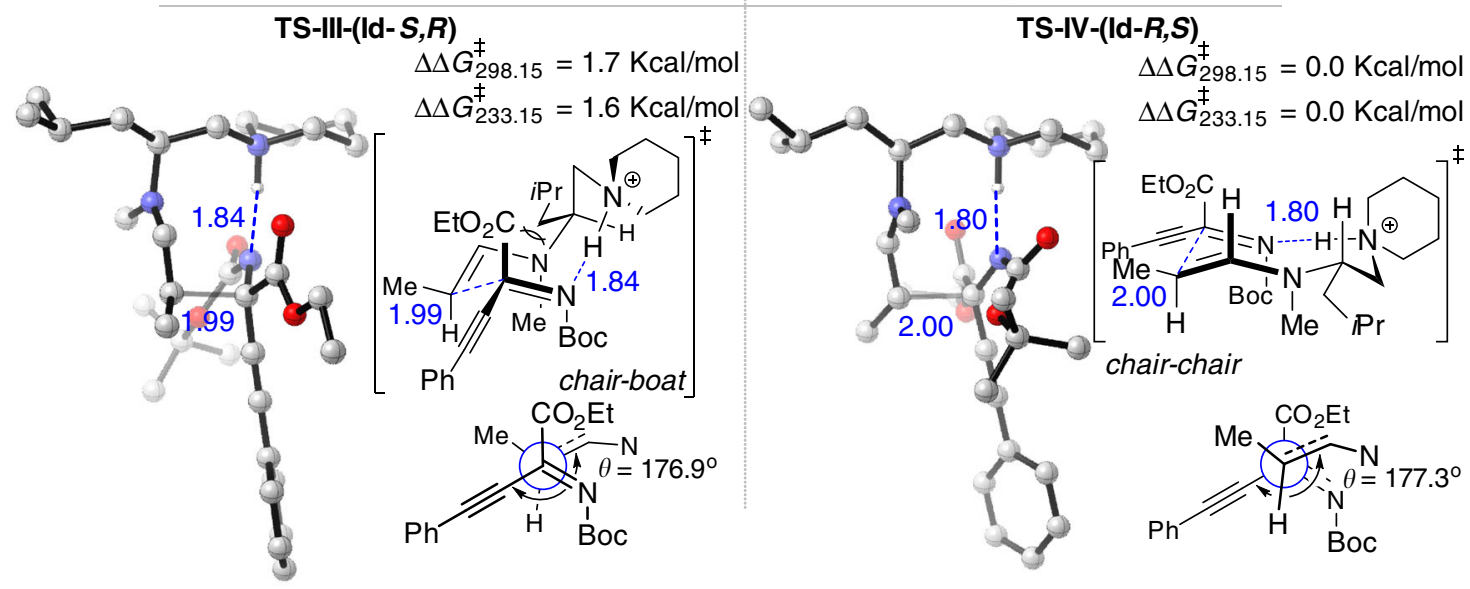

Fig. 2 Origin of the reversal of enantioselectivity. a Enamine intermediate conformations. $\mathbf{b}$ Transition-state models for the asymmetric Mannich reaction of ketimine $\mathbf{1 a}$ and aldehyde $\mathbf{2 a}$ catalyzed by $\mathbf{l a} / 0.5 \mathrm{TfOH}$ and $\mathbf{I d} / 0.5 \mathrm{TfOH}$

The above Mannich reactions are notable in that catalytic asymmetric enantiodivergent Mannich reactions between aldehydes and ketimines have not previously been reported ${ }^{55-59}$.

Cross-aldol reaction of aldehydes with isatins. Next, we sought to further establish the generality of designed enantiodivergent catalysis to test other classes of reactions. First, we targeted the catalytic asymmetric aldol reactions. Among them, the catalytic asymmetric direct cross-aldol reaction of aldehydes with isatins, which is a potentially useful method for the synthesis of chiral 3 -substituted 3-hydroxy-2-oxindoles ${ }^{60}$, was first tested. Only few chiral catalysts have been reported for this reaction, and only 4-halogen-substituted isatin substrates can furnish acceptable levels of diastereoselectivities ${ }^{61,62}$. When other isatins were used as substrates, poor diastereoselectivities (1.4:1-1.6:1 dr) were observed ${ }^{61-63}$. Pleasingly, we found that, in the presence of our acyclic chiral secondary amine If 


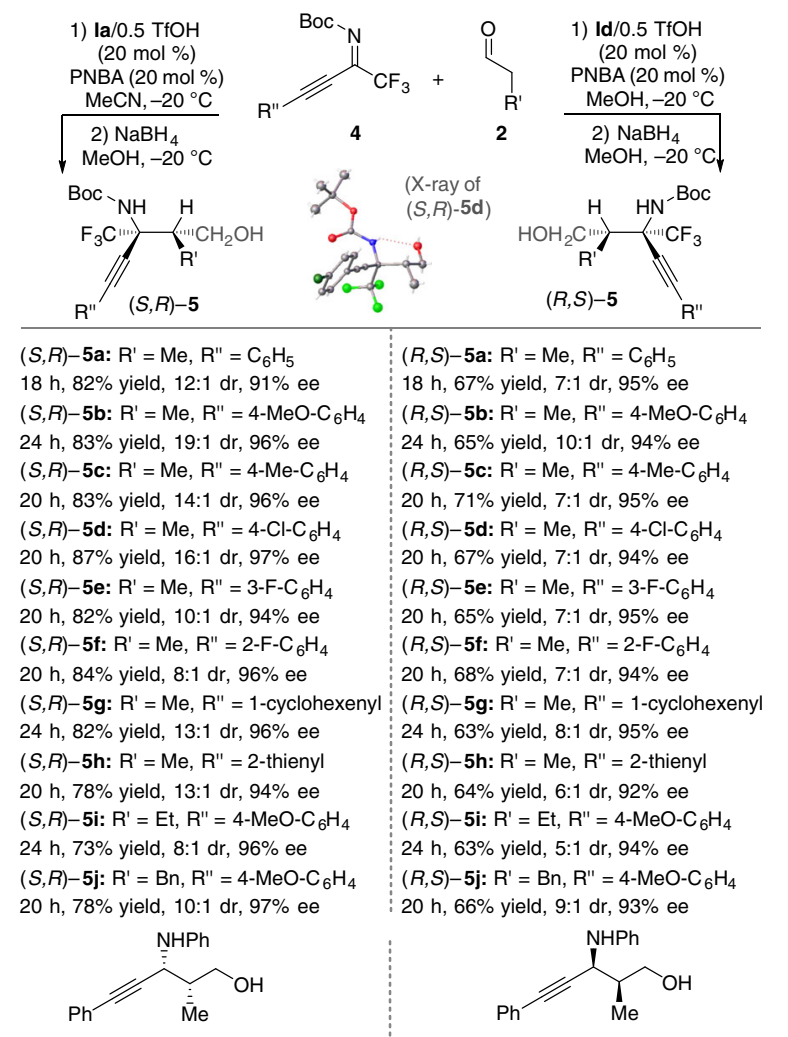

$(R, R)-\mathbf{5 k}^{\star}: 14 \mathrm{~h}, 82 \%$ yield, $16: 1 \mathrm{dr}, 94 \%$ ee $(S, S)-\mathbf{5} \mathbf{k}^{\star \star}: 18 \mathrm{~h}, \mathbf{7 5} \%$ yield, $10: 1 \mathrm{dr}, 87 \%$ ee

Fig. 3 Mannich reaction of trifluoromethyl alkynyl ketimines. Reaction conditions for the formation of $(S, R)-5: 4(0.1 \mathrm{mmol})$, PNBA $(0.02 \mathrm{mmol}$, $20 \mathrm{~mol} \%)$, la/ $0.5 \mathrm{TfOH}(20 \mathrm{~mol} \%), \mathbf{2}(0.3 \mathrm{mmol}), \mathrm{MeCN}(0.8 \mathrm{~mL})$, $-20^{\circ} \mathrm{C}$. Reaction conditions for the formation of $(R, S)-5: 4(0.1 \mathrm{mmol})$, PNBA (0.02 mmol, $20 \mathrm{~mol} \%)$, Id $/ 0.5 \mathrm{TfOH}(20 \mathrm{~mol} \%), 2(0.3 \mathrm{mmol})$, $\mathrm{MeOH}(0.8 \mathrm{~mL}),-20^{\circ} \mathrm{C}$. Single asterisk $\left(^{*}\right)$ : Without PNBA as the additive. Double asterisks $\left(^{\star \star}\right)$ : Without PNBA as the additive. MeCN as the solvent (The absolute and relative configuration of $\mathbf{5 k}$ was determined by comparison with the reported ref. ${ }^{50}$.)

$(N-i-\mathrm{Bu})$, various isatins can react smoothly to give the antialdol products $(R, R)-\mathbf{1 1}$ with both good diastereoselectivity and enantioselectivity (Fig. 6). The switch to Ig $(N-\mathrm{Me})$ resulted in a reversal in enantioselectivity, thus giving $(S, S)$-11 with both good diastereoselectivity and enantioselectivity. These reactions provide a highly stereoselective method for the catalytic asymmetric enantiodivergent synthesis of 3-substituted 3hydroxy-2-oxindoles ${ }^{60}$.

Aldehyde-aldehyde cross-aldol reaction. The designed enantiodivergent catalysis methodology was also applicable to the direct aldehyde-aldehyde cross-aldol reaction ${ }^{64,65}$. Ia $(\mathrm{N}-\mathrm{i}$-Bu) gave the anti-aldol products $(S, S)$-13, while $\mathbf{I h}(\mathrm{N}-\mathrm{Me})$ afforded the enantiomer products $(R, R)-13$ (Fig. 7). It should be noted that the chiral primary amine II was previously reported by Luo and co-workers ${ }^{66}$ for this reaction to give the complementary syn-selective aldol product $(S, R)-13$. Taken together, these reactions constitute a rare example where both enantiodivergence and diastereodivergence is achieved simply by a modest change within the catalyst architecture while maintaining the same absolute configuration.

a-Amination reaction of aldehydes. Finally, we explored the possibility of the designed enantiodivergent catalysis for the formation of single stereocenters and tested the $\alpha$-amination reaction of aldehydes ${ }^{67-69}$. Ii $(N-i-\mathrm{Bu})$ gave the $(S)$-configured
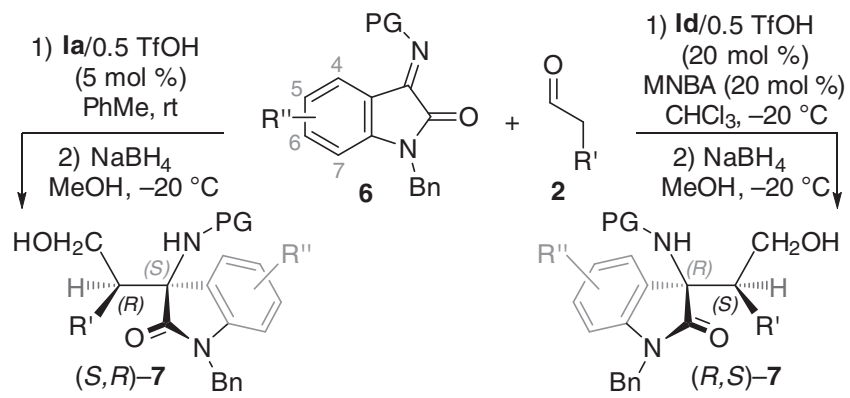

(PG $=$ Boc)

$(S, R)-7 \mathrm{a}: \mathrm{R}^{\prime}=\mathrm{Me}, \mathrm{R}^{\prime \prime}=\mathrm{H}$

$8 \mathrm{~h}, 89 \%,>20: 1 \mathrm{dr}, 94 \%$ ee

$(S, R)-7 \mathrm{~b}: \mathrm{R}^{\prime}=\mathrm{Et}, \mathrm{R}^{\prime \prime}=\mathrm{H}$

$4 \mathrm{~h}, 90 \%$ yield, $>20: 1 \mathrm{dr}, 96 \%$ ee

$(S, R)-7 \mathrm{c}: \mathrm{R}^{\prime}=\mathrm{Et}, \mathrm{R}^{\prime \prime}=5-\mathrm{OMe}$

$(P G=B o c)$

$(R, S)-7 a^{*}: R^{\prime}=\mathrm{Me}, \mathrm{R}^{\prime \prime}=\mathrm{H}$

$12 \mathrm{~h}, 94 \%$ yield, $>20: 1 \mathrm{dr}, 91 \%$ ee

$(R, S)-7 \mathrm{~b}: \mathrm{R}^{\prime}=\mathrm{Et}, \mathrm{R}^{\prime \prime}=\mathrm{H}$

$30 \mathrm{~h}, 86 \%$ yield, $>20: 1 \mathrm{dr}, 95 \%$ ee

$(S, R)-7 \mathrm{~d}: \mathrm{R}^{\prime}=\mathrm{Et}, \mathrm{R}^{\prime \prime}=6-\mathrm{Br}$

$14 \mathrm{~h}, 91 \%$ yield, $9: 1 \mathrm{dr}, 91 \%$ ee

$(R, S)-7 \mathrm{c}: \mathrm{R}^{\prime}=\mathrm{Et}, \mathrm{R}^{\prime \prime}=5-\mathrm{OMe}$

$7 \mathrm{~h}, 88 \%$ yield, $>20: 1 \mathrm{dr},>99 \%$ ee

$(S, R)-7 \mathrm{e}: \mathrm{R}^{\prime}=\mathrm{Et}, \mathrm{R}^{\prime \prime}=7-\mathrm{Cl}$

$32 \mathrm{~h}, 84 \%$ yield, $14: 1 \mathrm{dr}, 93 \%$ ee

$(S, R)-7 f: R^{\prime}=\mathrm{Bn}, \mathrm{R}^{\prime \prime}=\mathrm{H}$

$6 \mathrm{~h}, 89 \%$ yield, $>20: 1 \mathrm{dr}, 93 \%$ ee

$(S, R)-7 \mathrm{~g}: \mathrm{R}^{\prime}=$ allyl, $\mathrm{R}^{\prime \prime}=\mathrm{H}$

$10 \mathrm{~h}, 83 \%$ yield, $16: 1 \mathrm{dr}, 94 \%$ ee

$(S, R)-7 \mathrm{~h}: \mathrm{R}^{\prime}=n-\mathrm{Bu}, \mathrm{R}^{\prime \prime}=\mathrm{H}$,

$22 \mathrm{~h}, 88 \%$ yield, $>20: 1 \mathrm{dr}, 95 \%$ ee

$(\mathrm{PG}=\mathrm{Cbz})$

$(\mathrm{S}, R)-7 \mathrm{i}: \mathrm{R}^{\prime}=\mathrm{Me}, \mathrm{R}^{\prime \prime}=\mathrm{H}$

$16 \mathrm{~h}, 84 \%$ yield, $11: 1 \mathrm{dr}, 92 \%$ ee

$18 \mathrm{~h}, 93 \%$ yield, $10: 1 \mathrm{dr}, 90 \%$ ee

$(R, S)-7 \mathrm{~d}: \mathrm{R}^{\prime}=\mathrm{Et}, \mathrm{R}^{\prime \prime}=6-\mathrm{Br}$

$18 \mathrm{~h}, 92 \%$ yield, $>20: 1 \mathrm{dr}, 98 \%$ ee $(R, S)-7 \mathrm{e}: \mathrm{R}^{\prime}=\mathrm{Et}, \mathrm{R}^{\prime \prime}=7-\mathrm{Cl}$ $18 \mathrm{~h}, 92 \%$ yield, $9: 1 \mathrm{dr}, 92 \%$ ee $(R, S)-7 f: \mathrm{R}^{\prime}=\mathrm{Bn}, \mathrm{R}^{\prime \prime}=\mathrm{H}$

$14 \mathrm{~h}, 93 \%$ yield, $19: 1 \mathrm{dr}, 90 \%$ ee $(R, S)-7 g: \mathrm{R}^{\prime}=$ allyl, $\mathrm{R}^{\prime \prime}=\mathrm{H}$ $20 \mathrm{~h}, 91 \%$ yield, $8: 1 \mathrm{dr}, 90 \%$ ee

$(R, S)-7 \mathrm{~h}: \mathrm{R}^{\prime}=n-\mathrm{Bu}, \mathrm{R}^{\prime \prime}=\mathrm{H}$ $18 \mathrm{~h}, 90 \%$ yield, $11: 1 \mathrm{dr}, 92 \%$ ee $(\mathrm{PG}=\mathrm{Cbz})$

$(R, S)-7 i^{*}: \mathrm{R}^{\prime}=\mathrm{Me}, \mathrm{R}^{\prime \prime}=\mathrm{H}$

$16 \mathrm{~h}, 91 \%$ yield, $19: 1 \mathrm{dr}, 88 \%$ ee

Fig. 4 Enantiodivergent Mannich reaction of isatin ketimines. Reaction conditions for the formation of $(S, R)-\mathbf{7}: \mathbf{6}(0.1 \mathrm{mmol})$, la/ $0.5 \mathrm{TfOH}(5 \mathrm{~mol} \%)$, $2(0.2 \mathrm{mmol}), \mathrm{PhMe}(0.8 \mathrm{~mL})$, rt. Reaction conditions for the formation of $(R, S)-7: 6(0.1 \mathrm{mmol}), \mathrm{MNBA}(0.02 \mathrm{mmol}, 20 \mathrm{~mol} \%)$, Id $/ 0.5 \mathrm{TfOH}$ $(20 \mathrm{~mol} \%), 2(0.3 \mathrm{mmol}), \mathrm{CHCl}_{3}(0.8 \mathrm{~mL}),-20^{\circ} \mathrm{C}$. Single asterisk (*): PhMe was used as the solvent. MNBA m- $\mathrm{NO}_{2}-\mathrm{C}_{6} \mathrm{H}_{4} \mathrm{CO}_{2} \mathrm{H}, \mathrm{Cbz}$ benzyloxycarbonyl

aminated products, and the switch to Ie $(\mathrm{N}-\mathrm{Me})$ resulted in a reversal in enantioselectivity (Fig. 8).

\section{Discussion}

In summary, by designing a class of reactive and stereoselective acyclic chiral secondary amines as organocatalysts that are easily available and highly modular, we have developed a method for achieving the enantiodivergence, especially in challenging asymmetric transformations. Simple yet strategic modification of the secondary $N$-substituent (specifically, from $\mathrm{N}-\mathrm{i}$-Bu- to $\mathrm{N}$-Me- group) of secondary amine while maintaining the same absolute configuration of the catalysts led to a reversal of the enantioselectivity through conformation modulation of the catalyst. Besides the high level of stereocontrol achieved, this designed approach to enantiodivergent catalysis displays broad scope that is demonstrated in eight different transformations including seven reactions involving two prochiral reactants with simultaneous control of diastereoselectivity, all delivering both enantiomers of a range of structurally diverse products including hitherto less accessible yet important compounds in good yields with good stereoselectivities. The present study has made an advance in enantiodivergent organocatalysis. Also it showcases the potential of acyclic chiral secondary aminocatalysts in enantiodivergent catalysis as well as the unusual reactivity and stereoselectivity of acyclic chiral 


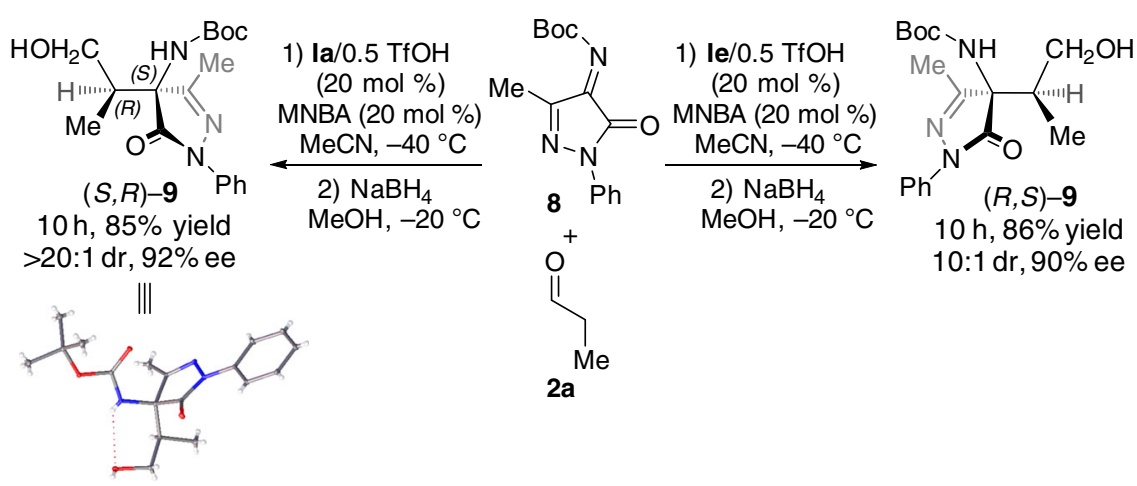

Fig. 5 Enantiodivergent Mannich reaction of monocyclic ketimines. Reaction conditions for the formation of $(S, R)-\mathbf{9}: 8(0.1 \mathrm{mmol})$, MNBA $(0.02 \mathrm{mmol}$, $20 \mathrm{~mol} \%)$, la/ $0.5 \mathrm{TfOH}(20 \mathrm{~mol} \%), \mathbf{2 a}(0.3 \mathrm{mmol}), \mathrm{MeCN}(0.8 \mathrm{~mL}),-40{ }^{\circ} \mathrm{C}$. Reaction conditions for the formation of $(R, S)-\mathbf{9}: \mathbf{8}(0.1 \mathrm{mmol}), \mathrm{MNBA}$ $(0.02 \mathrm{mmol}, 20 \mathrm{~mol} \%)$, le $/ 0.5 \mathrm{TfOH}(20 \mathrm{~mol} \%), \mathbf{2 a}(0.3 \mathrm{mmol}), \mathrm{MeCN}(0.8 \mathrm{~mL}),-40^{\circ} \mathrm{C}$

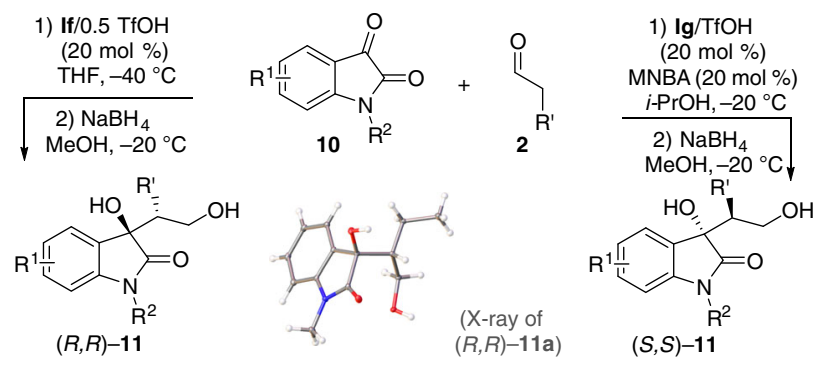

$(R, R)-11 \mathrm{a}: \mathrm{R}^{1}=\mathrm{H}, \mathrm{R}^{2}=\mathrm{Me}, \mathrm{R}^{\prime}=\mathrm{Et}$ $14 \mathrm{~h}, 81 \%, 11: 1 \mathrm{dr}, 90 \%$ ee (R,R)-11b: $\mathrm{R}^{1}=\mathrm{H}, \mathrm{R}^{2}=\mathrm{MOM}, \mathrm{R}^{\prime}=\mathrm{Et} \quad(S, S)-\mathbf{1 1 b}: \mathrm{R}^{1}=\mathrm{H}, \mathrm{R}^{2}=\mathrm{MOM}, \mathrm{R}^{\prime}=\mathrm{Et}$ $14 \mathrm{~h}, 80 \%, 10: 1 \mathrm{dr}, 91 \%$ ee $\quad 72 \mathrm{~h}, 65 \%, 12: 1 \mathrm{dr}, 90 \%$ ee $(R, R)-11 \mathrm{c}^{*}: \mathrm{R}^{1}=4-\mathrm{Br}, \mathrm{R}^{2}=\mathrm{Me}, \mathrm{R}^{\prime}=\mathrm{Et} \quad(S, S)-11 \mathrm{c}: \mathrm{R}^{1}=4-\mathrm{Br}, \mathrm{R}^{2}=\mathrm{Me}, \mathrm{R}^{\prime}=\mathrm{Et}$ $8 \mathrm{~h}, 87 \%,>20: 1 \mathrm{dr}, 94 \%$ ee $\quad 72 \mathrm{~h}, 63 \%, 15: 1 \mathrm{dr}, 86 \%$ ee $(R, R)-11 \mathrm{~d}: \mathrm{R}^{1}=5-\mathrm{OMe}, \mathrm{R}^{2}=\mathrm{Me}, \mathrm{R}^{\prime}=\mathrm{Et}_{(}(S, S)-11 \mathrm{~d}: \mathrm{R}^{1}=5-\mathrm{OMe}, \mathrm{R}^{2}=\mathrm{Me}, \mathrm{R}^{\prime}=\mathrm{Et}$ $24 \mathrm{~h}, 78 \%, 12: 1 \mathrm{dr}, 90 \%$ ee $\quad 72 \mathrm{~h}, 53 \%, 11: 1 \mathrm{dr}, 92 \%$ ee $(R, R)-11 \mathrm{e}: \mathrm{R}^{1}=5-\mathrm{Cl}, \mathrm{R}^{2}=\mathrm{Me}, \mathrm{R}^{\prime}=\mathrm{Et} \quad(S, S)-11 \mathrm{e}: \mathrm{R}^{1}=5-\mathrm{Cl}, \mathrm{R}^{2}=\mathrm{Me}, \mathrm{R}^{\prime}=\mathrm{Et}$ $14 \mathrm{~h}, 80 \%, 10: 1 \mathrm{dr}, 90 \%$ ee $\quad 72 \mathrm{~h}, 68 \%, 14: 1 \mathrm{dr}, 92 \%$ ee $(R, R)-11 f: \mathrm{R}^{1}=7-\mathrm{Br}, \mathrm{R}^{2}=\mathrm{Me}, \mathrm{R}^{\prime}=\mathrm{Et} \quad(S, S)-\mathbf{1 1 f}: \mathrm{R}^{1}=\mathbf{7}-\mathrm{Br}, \mathrm{R}^{2}=\mathrm{Me}, \mathrm{R}^{\prime}=\mathrm{Et}$ $14 \mathrm{~h}, 78 \%, 8: 1 \mathrm{dr}, 93 \%$ ee $\quad 72 \mathrm{~h}, 60 \%, 13: 1 \mathrm{dr}, 90 \%$ ee $(R, R)-11 \mathbf{g}^{\star \star}: \mathrm{R}^{1}=\mathrm{H}, \mathrm{R}^{2}=\mathrm{Me}, \mathrm{R}^{\prime}=n-\mathrm{Bu} \quad(S, S)-\mathbf{1 1 g}: \mathrm{R}^{1}=\mathrm{H}, \mathrm{R}^{2}=\mathrm{Me}, \mathrm{R}^{\prime}=n-\mathrm{Bu}$ $14 \mathrm{~h}, 77 \%, 8: 1 \mathrm{dr}, 91 \%$ ee $72 \mathrm{~h}, 75 \%, 10: 1 \mathrm{dr}, 90 \%$ ee

$$
i-\mathrm{Bu}_{\text {If }}-\mathrm{NH} \mathrm{Be}_{\mathrm{Bn}}^{\mathrm{N}^{-}-\mathrm{Et}} \mathrm{Me}_{\mathbf{l g}}^{-\mathrm{NH}}
$$

Fig. 6 Enantiodivergent cross-aldol reaction of isatins. Reaction conditions for the formation of $(R, R)-\mathbf{1 1}: \mathbf{1 0}(0.1 \mathrm{mmol})$, If $/ 0.5 \mathrm{TfOH}(20 \mathrm{~mol} \%), \mathbf{2}$ $(0.3 \mathrm{mmol})$, THF $(0.8 \mathrm{~mL}),-40^{\circ} \mathrm{C}$. Reaction conditions for the formation of (S,S)-11: 10 (0.1 mmol), MNBA (0.02 mmol, $20 \mathrm{~mol} \%)$, lg/TfOH (20 $\mathrm{mol} \%), 2(0.3 \mathrm{mmol}), i-\operatorname{PrOH}(0.8 \mathrm{~mL}),-20^{\circ} \mathrm{C}$. Single asterisk (*): Run at

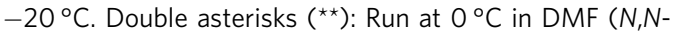
dimethylformamide)

secondary aminocatalysts, which are not observable with existing chiral amine catalysts.

\section{Methods}

Mannich reaction of $\boldsymbol{\beta}, \boldsymbol{\gamma}$-alkynyl- $\alpha$-imino esters by la. To a solution of $\beta, \gamma$ alkynyl- $\alpha$-imino ester $\mathbf{1}(0.1 \mathrm{mmol})$, 4-nitrobenzoic acid $(3.3 \mathrm{mg}, 0.02 \mathrm{mmol})$, and catalyst $\mathrm{Ia} / 0.5 \mathrm{TfOH}(6.7 \mathrm{mg}, 20 \mathrm{~mol} \%)$ in anhydrous $\mathrm{MeCN}(0.8 \mathrm{~mL})$ was added aldehyde $2(0.3 \mathrm{mmol})$ at $-40^{\circ} \mathrm{C}$. The reaction mixture was stirred at this temperature until 1 disappeared via thin-layer chromatography (TLC) detection. Then $\mathrm{NaBH}_{4}(19.2 \mathrm{mg}, 0.5 \mathrm{mmol})$ and $\mathrm{MeOH}(0.5 \mathrm{~mL})$ were added at $-20^{\circ} \mathrm{C}$. The resulting mixture was stirred for $0.5 \mathrm{~h}$, then recovered to room temperature and kept stirring for $1 \mathrm{~h}$. Finally, the resulting mixture was purified by silica gel column chromatography (ethyl acetate/petroleum ether $=1 / 10-1 / 5$ ) to afford the Mannich product $(S, R)-\mathbf{3}$.

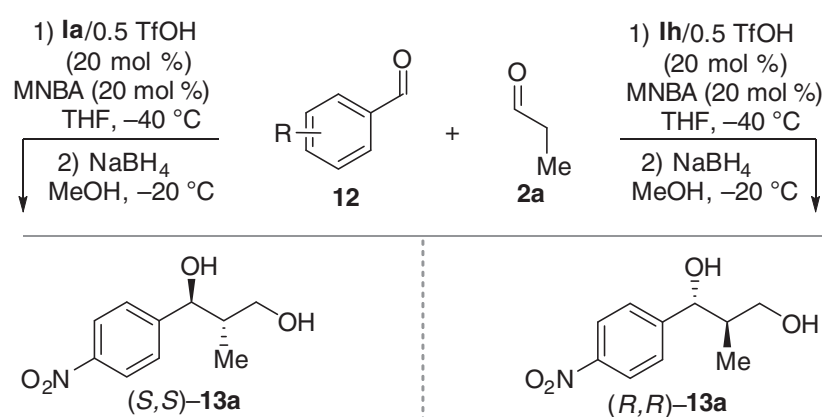

$14 \mathrm{~h}, 85 \%, 16: 1 \mathrm{dr}, 84 \%$ ee<smiles>C[C@@H](CO)[C@@H](O)c1ccc(Br)cc1</smiles>
$(S, S)-13 b^{*}$

$14 \mathrm{~h}, 67 \%, 12: 1 \mathrm{dr}, 81 \%$ ee<smiles>C[C@@H](CO)[C@@H](O)c1ccccc1</smiles>

$(S, S)-13 c^{*}$

$14 \mathrm{~h}, 62 \%, 12: 1 \mathrm{dr}, 82 \%$ ee<smiles>CCCNC(Cc1ccccc1)CN(Br)NC(=O)c1ccccc1</smiles><smiles>CC[C@@H](CN(CC)CC)NC</smiles>

Fig. 7 Enantiodivergent aldehyde-aldehyde cross-aldol reaction. Reaction conditions for the formation of (S,S)-13: 12 (0.1 mmol), MNBA (0.02 mmol, $20 \mathrm{~mol} \%)$, la/0.5TfOH (20 mol \%), 2a (0.3 mmol), THF $(0.8 \mathrm{~mL})$, $-40{ }^{\circ} \mathrm{C}$. Reaction conditions for the formation of $(R, R)-\mathbf{1 3}: 12(0.1 \mathrm{mmol})$, MNBA (0.02 mmol, $20 \mathrm{~mol} \%)$, Ih/0.5TfOH (20 mol \%), 2a (0.3 mmol), THF $(0.8 \mathrm{~mL}),-40{ }^{\circ} \mathrm{C}$. Single asterisk $\left(^{\star}\right)$ : Im/0.5 TfOH (20 mol \%) was used as the catalyst. The absolute and relative configuration of $\mathbf{1 3}$ was determined by comparison with the reported ref. 65

Mannich reaction of $\beta, \gamma$-alkynyl- $\alpha$-imino esters by Id. To a solution of $\beta, \gamma$ alkynyl- $\alpha$-imino ester $1(0.1 \mathrm{mmol})$, 4-nitrobenzoic acid $(3.3 \mathrm{mg}, 0.02 \mathrm{mmol})$, and catalyst Id/0.5TfOH $(5.6 \mathrm{mg}, 20 \mathrm{~mol} \%)$ in anhydrous DCE $(0.8 \mathrm{~mL})$ was added aldehyde $2(0.3 \mathrm{mmol})$ at $-40^{\circ} \mathrm{C}$. The reaction mixture was stirred at this temperature until 1 disappeared via TLC detection. Then $\mathrm{NaBH}_{4}(19.2 \mathrm{mg}, 0.5 \mathrm{mmol})$ and $\mathrm{MeOH}(0.5 \mathrm{~mL})$ were added at $-20^{\circ} \mathrm{C}$. The resulting mixture was stirred for $0.5 \mathrm{~h}$, then recovered to room temperature and kept stirring for $1 \mathrm{~h}$. Finally, the resulting mixture was purified by silica gel column chromatography (ethyl acetate/petroleum ether $=1 / 10-1 / 5)$ to afford the Mannich product $(R, S)-3$. 


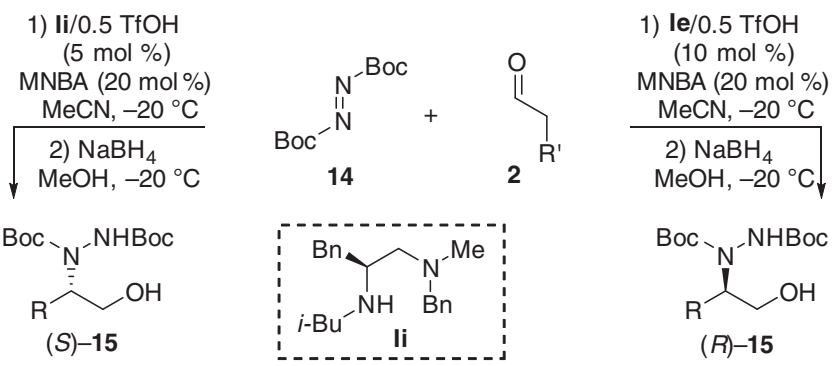

(S)-15a: R = Et, 2 h, 91\%, 90\% ee $\quad(R)-15 a: R=E t, 2 ~ h, 93 \%, 90 \%$ ee (S)-15b: $\mathrm{R}=\mathrm{Me}, 2 \mathrm{~h}, 88 \%, 90 \%$ ee $\quad(R)-15 \mathrm{~b}: \mathrm{R}=\mathrm{Me}, 3 \mathrm{~h}, 92 \%, 90 \%$ ee

Fig. 8 Enantiodivergent $\alpha$-amination of aldehydes. Reaction conditions for the formation of (S)-15: $14(0.1 \mathrm{mmol}), \operatorname{MNBA}(0.02 \mathrm{mmol}, 20 \mathrm{~mol} \%)$, li/ $0.5 \mathrm{TfOH}(5 \mathrm{~mol} \%), 2(0.3 \mathrm{mmol}), \mathrm{MeCN}(0.8 \mathrm{~mL}),-20^{\circ} \mathrm{C}$. Reaction conditions for the formation of (R)-15: $14(0.1 \mathrm{mmol})$, MNBA (0.02 mmol, 20 $\mathrm{mol} \%$ ), le $/ 0.5 \mathrm{TfOH}(10 \mathrm{~mol} \%), 2(0.3 \mathrm{mmol}), \mathrm{MeCN}(0.8 \mathrm{~mL}),-20^{\circ} \mathrm{C}$. The absolute configuration of $\mathbf{1 5}$ was determined by comparison with the reported ref. 69

Aldol reaction of isatins by If. To a solution of isatin $\mathbf{1 0}(0.1 \mathrm{mmol})$ and catalyst If $/ 0.5 \mathrm{TfOH}(7.9 \mathrm{mg}, 20 \mathrm{~mol} \%)$ in anhydrous THF $(0.8 \mathrm{~mL})$ was added aldehyde 2 $(0.3 \mathrm{mmol})$ at $-40^{\circ} \mathrm{C}$. The reaction mixture was stirred at this temperature until 10 disappeared via TLC detection. Then $\mathrm{NaBH}_{4}(19.2 \mathrm{mg}, 0.5 \mathrm{mmol})$ and $\mathrm{MeOH}(0.4$ $\mathrm{mL}$ ) were added at $-20^{\circ} \mathrm{C}$, and the resulting mixture was stirred for $0.5 \mathrm{~h}$. Finally, the resulting mixture was purified by silica gel column chromatography (ethyl acetate/petroleum ether $=1 / 5-1 / 1)$ to afford the Mannich product $(R, R)-11$.

Aldol reaction of isatins by $\mathbf{l g}$. To a solution of isatin $\mathbf{1 0}(0.1 \mathrm{mmol}), 3$ nitrobenzoic acid $(3.3 \mathrm{mg}, 0.02 \mathrm{mmol})$, and catalyst $\mathbf{I g} / \mathrm{TfOH}(6.7 \mathrm{mg}, 20 \mathrm{~mol} \%)$ in anhydrous $i$ - $\mathrm{PrOH}(0.8 \mathrm{~mL})$ was added aldehyde $2(0.3 \mathrm{mmol})$ at $-20{ }^{\circ} \mathrm{C}$. The reaction mixture was stirred at this temperature until 10 disappeared via TLC detection. Then $\mathrm{NaBH}_{4}(19.2 \mathrm{mg}, 0.5 \mathrm{mmol})$ and $\mathrm{MeOH}(0.4 \mathrm{~mL})$ were added at $-20^{\circ} \mathrm{C}$, and the resulting mixture was stirred for $0.5 \mathrm{~h}$. Finally, the resulting mixture was purified by silica gel column chromatography (ethyl acetate/petroleum ether $=1 / 5-1 / 1)$ to afford the Mannich product $(S, S)-11$.

\section{Data availability}

The authors declare that the data supporting the findings of this study are available within the article and the Supplementary Information as well as from the authors upon reasonable request. The X-ray crystallographic coordinates for structures $(S, R)-\mathbf{3 a},(S, R)$ 5d, $(S, R)-9$, and $(R, R)-11$ a reported in this study have been deposited at the Cambridge Crystallographic Data Centre (CCDC), under CCDC 1893083, CCDC 1893081, CCDC 1893084 , and CCDC 1857209, respectively. These data can be obtained free of charge from The Cambridge Crystallographic Data Centre via www.ccdc.cam.ac.uk/ data_request/cif.

Received: 10 June 2019; Accepted: 28 October 2019; Published online: 15 November 2019

\section{References}

1. Drug Stereochemistry: Analytical Methods and Pharmacology 3rd edn (eds Jóźwiak, K., Lough, W. J. \& Wainer, I. W.) (CRC Press, Boca Raton, FL, 2012).

2. Zhang, A. P., Xie, X. M. \& Liu, W. P. Enantioselective separation and phytotoxicity on rice seedlings of Paclobutrazol. J. Agric. Food Chem. 59, 4300-4305 (2017).

3. Kim, Y. H. Dual enantioselective control in asymmetric synthesis. Acc. Chem. Res. 34, 955-962 (2001).

4. Zanoni, G., Castronovo, F., Franzini, M., Vidari, G. \& Giannini, E. Toggling enantioselective catalysis-a promising paradigm in the development of more efficient and versatile enantioselective synthetic methodologies. Chem. Soc. Rev. 32, 115-129 (2003).

5. Tanaka, T. \& Hayashi, M. New approach for complete reversal of enantioselectivity using a single chiral source. Synthesis 2008, 3361-3376 (2008).

6. Bartók, M. Unexpected inversions in asymmetric reactions: reactions with chiral metal complexes, chiral organocatalysts, and heterogeneous chiral catalysts. Chem. Rev. 110, 1663-1705 (2010).
7. Escorihuela, J., Burguete, M. I. \& Luis, S. V. New advances in dual stereocontrol for asymmetric reactions. Chem. Soc. Rev. 42, 5595-5617 (2013).

8. Zhan, G., Du, W. \& Chen, Y.-C. Switchable divergent asymmetric synthesis via organocatalysis. Chem. Soc. Rev. 46, 1675-1692 (2017).

9. Krautwald, S. \& Carreira, E. M. Stereodivergence in asymmetric catalysis. J. Am. Chem. Soc. 139, 5627-5639 (2019).

10. Romanazzi, G., Degennaro, L., Mastrorilli, P. \& Luisi, R. Chiral switchable catalysts for dynamic control of enantioselectivity. ACS Catal. 7, 4100-4114 (2017).

11. Beletskaya, I. P., Nájera, C. \& Yus, M. Stereodivergent catalysis. Chem. Rev. 118, 5080-5200 (2018).

12. Sohtome, Y., Tanaka, S., Takada, K., Yamaguchi, T. \& Nagasawa, K. Solventdependent enantiodivergent Mannich-type reaction: utilizing a conformationally flexible guanidine/bisthiourea organocatalyst. Angew. Chem. Int. Ed. 49, 9254-9257 (2010).

13. Hua, M.-Q., Cui, H.-F., Wang, L., Nie, J. \& Ma, J.-A. Reversal of enantioselectivity by tuning the conformational flexibility of phase-transfer catalysts. Angew. Chem. Int. Ed. 49, 2772-2776 (2010).

14. Wang, J. \& Feringa, B. L. Dynamic control of chiral space in a catalytic asymmetric reaction using a molecular motor. Science 331, 1429-1432 (2011).

15. Mortezaei, S., Catarineu, N. R. \& Canary, J. W. A redox-reconfigurable, ambidextrous asymmetric catalyst. J. Am. Chem. Soc. 134, 8054-8057 (2012).

16. Wang, J., Chen, J., Kee, C. W. \& Tan, C.-H. Enantiodivergent and $\gamma$-selective asymmetric allylic amination. Angew. Chem. Int. Ed. 51, 2382-2386 (2012).

17. Garzan, A. et al. Solvent-dependent enantiodivergence in the chlorocyclization of unsaturated carbamates. Chem. Eur. J. 19, 9015-9021 (2013).

18. Moteki, S. A. et al. An achiral-acid-induced switch in the enantioselectivity of a chiral cis-diamine-based organocatalyst for asymmetric aldol and Mannich reactions. Angew. Chem. Int. Ed. 51, 1187-1190 (2012).

19. Fukata, Y., Asano, K. \& Matsubara, S. Procedure-controlled enantioselectivity switch in organocatalytic 2-oxazolidinone synthesis. J. Am. Chem. Soc. 135, 12160-12163 (2013).

20. Mori, K., Itakura, T. \& Akiyama, T. Enantiodivergent atroposelective synthesis of chiral biaryls by asymmetric transfer hydrogenation: chiral phosphoric acid catalyzed dynamic kinetic resolution. Angew. Chem. Int. Ed. 55, 11642-11646 (2016).

21. Galván, A. et al. Exploiting the multidentate nature of chiral disulfonimides in a multicomponent reaction for the asymmetric synthesis of pyrrolo[1,2-a] indoles: a remarkable case of enantioinversion. Angew. Chem. Int. Ed. 55, 3428 (2016).

22. You, Y., Zhang, L. \& Luo, S. Reagent-controlled enantioselectivity switch for the asymmetric fluorination of $\beta$-ketocarbonyls by chiral primary amine catalysis. Chem. Sci. 8, 621-626 (2017).

23. Macharia, J. et al. A designed approach to enantiodivergent enamine catalysis Angew. Chem. Int. Ed. 56, 8756-8760 (2017).

24. Nakayama, K. \& Maruoka, K. Complete switch of product selectivity in asymmetric direct aldol reaction with two different chiral organocatalysts from a common chiral source. J. Am. Chem. Soc. 130, 17666-17667 (2008).

25. Notz, W., Tanaka, F. \& Barbas, C. F. III Enamine-based organocatalysis with proline and diamines: the development of direct catalytic asymmetric aldol, Mannich, Michael, and Diels-Alder reactions. Acc. Chem. Res. 37, 580-591 (2004).

26. Lelais, G. \& MacMillan, D. W. C. Modern strategies in organic catalysis: the advent and development of iminium activation. Aldrichim. Acta 39, 79-87 (2006).

27. Mukherjee, S., Yang, J. W., Hoffmann, S. \& List, B. Asymmetric enamine catalysis. Chem. Rev. 107, 5471-5569 (2007)

28. Erkkilä, A., Majander, I. \& Pihko, P. M. Iminium catalysis. Chem. Rev. 107, 5416-5470 (2007).

29. Melchiorre, P., Marigo, M., Carlone, A. \& Bartoli, G. Asymmetric aminocatalysis-gold rush in organic chemistry. Angew. Chem. Int. Ed. 47, 6138-6171 (2008).

30. Mielgo, A. \& Palomo, C. $\alpha, \alpha$-Diarylprolinol ethers: new tools for functionalization of carbonyl compounds. Chem. Asian J. 3, 922-948 (2008).

31. Melchiorre, P. Cinchona-based primary amine catalysis in the asymmetric functionalization of carbonyl compounds. Angew. Chem. Int. Ed. 51, 9748-9770 (2012).

32. Jensen, K. L., Dickmeiss, G., Jiang, H., Albrecht, Ł. \& Jørgensen, K. A. The diarylprolinol silyl ether system: a general organocatalyst. Acc. Chem. Res. 45, 248-264 (2012).

33. Zhang, L., Fu, N. \& Luo, S. Pushing the limits of aminocatalysis: enantioselective transformations of $\alpha$-branched $\beta$-ketocarbonyls and vinyl ketones by chiral primary amines. Acc. Chem. Res. 48, 986-997 (2015).

34. Kano, T. \& Maruoka, K. Unique properties of chiral biaryl-based secondary amine catalysts for asymmetric enamine catalysis. Chem. Sci. 4, 907-915 (2013). 
35. Blanco, V., Leigh, D. A., Marcos, V., Morales-Serna, J. A. \& Nussbaumer, A. L. A switchable [2]Rotaxane asymmetric organocatalyst that utilizes an acyclic chiral secondary amine. J. Am. Chem. Soc. 136, 4905-4908 (2014).

36. Lauder, K., Toscani, A., Scalacci, N. \& Castagnolo, D. Synthesis and reactivity of propargylamines in organic chemistry. Chem. Rev. 117, 14091-14200 (2017).

37. Quasdorf, K. W. \& Overman, L. E. Catalytic enantioselective synthesis of quaternary carbon stereocentres. Nature 516, 181-191 (2014).

38. Riant, O. \& Hannedouche, J. Asymmetric catalysis for the construction of quaternary carbon centres: nucleophilic addition on ketones and ketimines. Org. Biomol. Chem. 5, 873-888 (2007).

39. Shibasaki, M. \& Kanai, M. Asymmetric synthesis of tertiary alcohols and $\alpha$ tertiary amines via $\mathrm{Cu}$-catalyzed $\mathrm{C}-\mathrm{C}$ bond formation to ketones and ketimines. Chem. Rev. 108, 2853-2873 (2008).

40. Trost, B. M., Hung, C.-I. \& Scharf, M. J. Direct catalytic asymmetric vinylogous additions of $\alpha, \beta$ - and $\beta, \gamma$-butenolides to polyfluorinated alkynyl ketimines. Angew. Chem. Int. Ed. 57, 11408-11412 (2018).

41. Hatano, M. et al. Enantioselective aza-Friedel-Crafts reaction of furan with $\alpha$ ketimino esters induced by a conjugated double hydrogen bond network of chiral bis(phosphoric acid) catalysts. Chem. Sci. 9, 6361-6367 (2018).

42. Yao, Y., Li, J., Zhou, Q., Dong, L. \& Chen, Y.-C. Enantioselective aza-MoritaBaylis-Hillman reaction with ketimines and acrolein catalyzed by organic assemblies. Chem. Eur. J. 19, 9447-9451 (2013).

43. Huang, G., Yin, Z. \& Zhang, X. Construction of optically active quaternary propargyl amines by highly enantioselective zinc/BINOL catalyzed alkynylation of ketoimines. Chem. Eur. J. 19, 11992-11998 (2013).

44. Hashimoto, T., Omote, M. \& Maruoka, K. Catalytic asymmetric alkynylation of C1-substituted C,N-cyclic azomethine imines by $\mathrm{CuI} /$ chiral Brønsted acid co-catalyst. Angew. Chem. Int. Ed. 50, 8952-8955 (2011).

45. Yin, L. et al. Direct catalytic asymmetric alkynylation of ketoimines. Org. Lett. 15, 698-701 (2013).

46. Hattori, G., Yoshida, A., Miyake, Y. \& Nishibayashi, Y. Enantioselective ringopening reactions of racemic ethynyl epoxides via copper-allenylidene intermediates: efficient approach to chiral $\beta$-amino alcohols. J. Org. Chem. 74, 7603-7607 (2009).

47. Gómez-Bengoa, E. et al. Combined $\alpha, \alpha$-dialkylprolinol ether/Brønsted acid promotes Mannich reactions of aldehydes with unactivated imines. An entry to anti-configured propargylic amino alcohols. Chem. Sci. 3, 2949-2957 (2012).

48. Hayashi, Y., Yamazaki, T., Kawauchi, G. \& Sato, I. Prolinate salt as a catalyst in the syn-selective, asymmetric Mannich reaction of alkynyl imine. Org. Lett. 20, 2391-2394 (2018).

49. Kano, T., Aota, Y., Asakawa, D. \& Maruoka, K. Brønsted acid-catalyzed Mannich reaction through dual activation of aldehydes and N-Boc-imines. Chem. Commun. 51, 16472-16474 (2015).

50. Lapuerta, I., Vera, S., Oiarbide, M. \& Palomo, C. Development of a syn selective Mannich reaction of aldehydes with propargylic imines by dual catalysis: asymmetric synthesis of functionalized propargylic amines. Chem. Eur. J. 22, 7229-7237 (2016)

51. Chen, S. \& Houk, K. N. Origins of stereoselectivity in Mannich reactions catalyzed by chiral vicinal diamines. J. Org. Chem. 83, 3171-3176 (2018).

52. Nie, J., Guo, H.-C., Cahard, D. \& Ma, J.-A. Asymmetric construction of stereogenic carbon centers featuring a trifluoromethyl group from prochiral trifluoromethylated substrates. Chem. Rev. 111, 455-529 (2011).

53. Kaur, J. \& Chimni, S. S. Catalytic synthesis of 3-aminooxindoles via addition to isatin imine: an update. Org. Biomol. Chem. 16, 3328-3347 (2018).

54. Mahajan, S. et al. Enantioselective synthesis of pyrazolone $\alpha$-aminonitrile derivatives via an organocatalytic Strecker reaction. Chem. Commun. 53, 6633-6636 (2017).

55. Zhuang, W., Saaby, S. \& Jørgensen, K. A. Direct organocatalytic enantioselective Mannich reactions of ketimines: an approach to optically active quaternary $\alpha$-amino acid derivatives. Angew. Chem. Int. Ed. 43, 4476-4478 (2004).

56. Kano, T., Song, S., Kubota, Y. \& Maruoka, K. Highly diastereo- and enantioselective Mannich reactions of synthetically flexible ketimines with secondary amine organocatalysts. Angew. Chem. Int. Ed. 51, 1191-1194 (2012).

57. Li, L., Han, M., Xiao, M. \& Xie, Z. Proline-catalyzed enantioselective synthesis of aza-quaternary carbon derivatives. Synlett 2011, 1727-1730 (2011).

58. Rueping, M., Rasappan, R. \& Raja, S. Asymmetric proline-catalyzed addition of aldehydes to $3 \mathrm{H}$-indol-3-ones: enantioselective synthesis of 2,3-dihydro$1 \mathrm{H}$-indol-3-ones with quaternary stereogenic centers. Helv. Chim. Acta 95, 2296-2303 (2012).

59. Dai, J. et al. Chiral primary amine catalysis for asymmetric Mannich reactions of aldehydes with ketimines: stereoselectivity and reactivity. Angew. Chem. Int. Ed. 56, 12697-12701 (2017).

60. Kumar, A. \& Chimni, S. S. Catalytic asymmetric synthesis of 3-hydroxyoxindole: a potentially bioactive molecule. RSC Adv. 2, 9748-9762 (2012).
61. Xue, F., Zhang, S., Liu, L., Duan, W. \& Wang, W. Organocatalytic enantioselective cross-aldol reactions of aldehydes with isatins: formation of two contiguous quaternary centered 3-substituted 3-hydroxyindol-2-ones. Chem. Asian J. 4, 1664-1667 (2009).

62. Hara, N., Nakamura, S., Shibata, N. \& Toru, T. First enantioselective synthesis of $(R)$-convolutamydine $\mathrm{B}$ and $\mathrm{E}$ with $\mathrm{N}$-(heteroarenesulfonyl)prolinamides. Chem. Eur. J. 15, 6790-6793 (2009).

63. Guo, Q. \& Zhao, J. C.-G. Primary amine catalyzed aldol reaction of isatins and acetaldehyde. Tetrahedron Lett. 53, 1768-1771 (2012).

64. Northrup, A. B. \& MacMillan, D. W. C. The first direct and enantioselective cross-aldol reaction of aldehydes. J. Am. Chem. Soc. 124, 6798-6799 (2002).

65. Gao, Q., Liu, Y., Lu, S.-M., Li, J. \& Li, C. Recyclable enamine catalysts for asymmetric direct cross-aldol reaction of aldehydes in emulsion media. Green Chem. 13, 1983-1985 (2011).

66. Li, J., Fu, N., Li, X., Luo, S. \& Cheng, J.-P. Chiral primary-tertiary diamineBrønsted acid salt catalyzed syn-selective cross-aldol reaction of aldehydes. J. Org. Chem. 75, 4501-4507 (2010).

67. Bøgevig, A., Juhl, K., Kumaragurubaran, N., Zhuang, W. \& Jørgensen, K. A. Direct organo-catalytic asymmetric $\alpha$-amination of aldehydes-a simple approach to optically active $\alpha$-amino aldehydes, $\alpha$-amino alcohols, and $\alpha$ amino acids. Angew. Chem. Int. Ed. 41, 1790-1793 (2002).

68. List, B. Direct catalytic asymmetric $\alpha$-amination of aldehydes. J. Am. Chem. Soc. 124, 5656-5657 (2002).

69. Cui, Z. \& Du, D.-M. Enantioselective synthesis of $\beta$-hydrazino alcohols using alcohols and $N$-Boc-hydrazine as substrates. Org. Lett. 18, 5616-5619 (2016).

\section{Acknowledgements}

This work was supported by the Program for the National Natural Science Foundation of China (21672184, 21861042, 21801221), the Program for Changjiang Scholars and Innovative Research Team in University (IRT17R94), the Program for Innovative Research Team (in Science and Technology) in University of Yunnan Province, Yunnan Province Government (YNQR-QNRC-2018-005), and YunLing Scholar of Yunnan Province.

\section{Author contributions}

Z.S. conceived and directed the project. J.D. and Z.W. performed the experiments. L.Z. and Y.L. performed DFT calculations. Y.D., F.P., and Z.S. analyzed the results. Z.S. wrote the manuscript.

\section{Competing interests}

The authors declare no competing interests.

\section{Additional information}

Supplementary information is available for this paper at https://doi.org/10.1038/s41467019-13183-5.

Correspondence and requests for materials should be addressed to Y.L. or Z.S.

Peer review information Nature Communications thanks Mathew Vetticatt and the other anonymous reviewer(s) for their contribution to the peer review of this work. Peer reviewer reports are available.

Reprints and permission information is available at http://www.nature.com/reprints

Publisher's note Springer Nature remains neutral with regard to jurisdictional claims in published maps and institutional affiliations.

pen Access This article is licensed under a Creative Commons Attribution 4.0 International License, which permits use, sharing, adaptation, distribution and reproduction in any medium or format, as long as you give appropriate credit to the original author(s) and the source, provide a link to the Creative Commons license, and indicate if changes were made. The images or other third party material in this article are included in the article's Creative Commons license, unless indicated otherwise in a credit line to the material. If material is not included in the article's Creative Commons license and your intended use is not permitted by statutory regulation or exceeds the permitted use, you will need to obtain permission directly from the copyright holder. To view a copy of this license, visit http://creativecommons.org/ licenses/by/4.0/.

(C) The Author(s) 2019 